The Journal of Animal \& Plant Sciences, 31(1): 2021, Page: 221-234

ISSN (print): 1018-7081; ISSN (online): 2309-8694

\title{
DIVERSITY MAINTENANCE OF SOME BARLEY (HORDEUM SPP) GENETIC RESOURCES USING SSR-BASED MARKER
}

\author{
N. Abdul-Razzak Tahir ${ }^{1}$, N. S. Ahmad ${ }^{2}$, K. M. Mustafa ${ }^{2}$ and D. D. L. Kareem ${ }^{2}$ \\ 1; Horticulture Department, College of Agricultural Engineering Sciences, University of Sulaimani, Sulaimani, Iraq, \\ Postcode 46011 \\ 2; Biotechnology and Crop Science Department, College of Agricultural Engineering Sciences, University of Sulaimani, \\ Sulaimani, Iraq, Postcode 46011 \\ Corresponding author's e-mail: nariman.ahmad@univsul.edu.iq
}

\begin{abstract}
Barley is an important cereal crop cultivated in many parts of the world since ancient times. Genetic diversity was studied in a set of 16 barley (Hordeum spp) genotypes using 25 microsatellite (SSR) loci. A total of 94 different alleles distributed over all the seven chromosomes of barley. Out of these, 76 alleles were polymorphic with an average of 3.04 alleles/primer. Major allele frequency, gene diversity and PIC were estimated based on allele frequencies, having the mean values of $0.543,0.571$ and 0.513 , respectively. Principal component analysis indicated the presence of high genetic variability among barley genotypes. ATACO, Canela, Local Abiad Sulaimani and Amal2 were identified to be highly distanced from other genotypes. The dendrogram created by hierarchical cluster analysis using the UPGMA algorithm was able to discriminate the genotypes into 7 groups according to their genetic distance. Both analyses parallel to principal coordinate analysis are indicating the close relatedness between Quinn, Zanbaka, Al-khair and Arta/3/Avar genotypes that exchange genetic material through continuous previous breeding programs. These values indicate high differentiation ability of SSR markers for genetic studies in barley and their utility for barley genetics and breeding.
\end{abstract}

Keywords: Allele, Barley, Genetic diversity, Polymorphic Information Content, Simple Sequence Repeat.

https://doi.org/10.36899/JAPS.2021.1.0209

Published online August 26, 2020

\section{INTRODUCTION}

Barley (Hordeum vulgare L.) is considered to be one of the ancient cereals crops that was domesticated around $8000 \mathrm{BC}$ from its wild relatives in Fertile Crescent of the Middle East (Kling et al., 2004; Dai et al., 2012). Later studies also hypothesized the occurrence of barley domestication in a wide region of the Eastern Mediterranean region of Western Asia (Poets et al., 2015). In addition to its commercial value as a feed or malt grain crop, barley is regaining popularity in human diet due to the rich content of antioxidant and b-glucan (Newman and Newman, 2008). Barley is one of the cereal crops that played a significant role in the development of agriculture. It represents the fourth most important cereal crops globally, after wheat, maize and rice (Tricase et al., 2018; FAOSTAT, 2019).

Barley is an annual autogamous grain crop that has early maturation and high drought tolerance (Sallam et al., 2019), grown in varied and marginal environments (Lister et al., 2018), making the crop to be widely distributed around the world (Garstang et al., 2011; Carter et al., 2019), tolerating wide range of biotic and abiotic stresses (Dawson et al., 2015).

It is second to wheat as the most important nutritional grain crops grown in low rainfall environments (Mohamed and Adel, 2012), providing a reasonable yield in marginal and drought areas (Baum et al., 2004).

There are over 32 species for Hordeum genus throughout the world to include diploid, polyploid, perennial, and annual types (Bothmer et al., 2009). Both six-rowed (Hordeum vulgare L. hexastichum) and tworowed barley (Hordeum vulgare L. distichum) emerged during the process of their domestication and selection (Kilian et al., 2006), It is also reported that the six-rowed barley is derived from the two-rowed wild barley as a result of mutations and selection pressure to give different spikelets morphologically (Komatsuda et al., 2007). The cultivated barley diploid species $(2 n=2 x=14)$ is a self-pollinating with a genome size of approximately $5100 \mathrm{Mbp}$ of a haploid nucleus (Wicker et al., 2017). It is realized that in barley genetic bottlenecks occurred during domestication and modern improvement programs. as current elite varieties hold less diversity compared to their wild relatives or landraces (Kilian et al., 2006; Prada, 2009).

Genetic diversity among and within plant species is in danger of being reduced. In wild species, genetic diversity might be lost because of severe reduction in population size, whereas in domesticated crops genetic diversity may be lost due to narrowing of genetic base during consequent breeding programs to produce commercial varieties (Govindaraj et al., 2015) 
Regularly, using elite crop germplasm as parents for breeding programs along with farmer performance creates genetic erosion and reducing genetic diversity (Duvick, 2005; Chaudhary, 2013), leading to more genetic uniformity.

The availability of genetic diversity among genotypes is a prerequisite and important step in the development of new and elite cultivars (Singh et al., 2014; Govindaraj et al., 2015). Diversity study is particularly useful in the characterization of cultivars for choosing right parent for breeding hybrids (Jaiswal et al., 2010). The efficient evaluation of barley's genetic diversity is necessary for efficient development in breeding programs for creation of superior cultivars, pattern of population structure (Amezrou et al., 2018) and effective conservation of this plant (Malysheva-Otto et al., 2006).

Traditionally, morphological characters have been used to evaluate the diversity and their relatedness. Besides been labor intensive, this method is often thought to be influenced by environmental conditions (Bosch et al., 2014). Rapid molecular marker application has been developed to eliminate crop-stage dependency and extensive field trials. Techniques of DNA fingerprinting especially those based on polymerase chain reaction have been established, and they are currently available (Jaiswal et al., 2010). Advances in DNA technology have increased the number and types of molecular marker for studying the genetic diversity of plant species. DNA markers are highly reproducible, independent of environmental factors, and are considered to be a valuable tool to provide precise insights into the diversity available for crop species (Nadeem et al., 2018). Different molecular markers (AFLP, ISSR, S-SAP, SSR and SNPs) have been used to characterize germplasm and investigate genetic diversity (Sorkheh et al., 2017; Jasim Aljumaili et al., 2018). Due to the high level of polymorphism and ease of use, SSR markers are widely used in crops breeding, accelerating the efficiency of cereals improvement (Hayden et al., 2008; Lenaerts et al., 2019). They are also abundant, dispersed throughout the genome, having the advantages of high variability from co-dominant and multi-allelic polymorphisms, and accurate and rapid detection (Ahmad et al., 2018; Liu et al., 2018; Viruel et al., 2018; Curto et al., 2019).

SSR markers have been extensively used in barley genetic diversity (Elakhdar et al., 2016a; Ferreira et al., 2016; Elakhdar et al., 2018; Arya et al., 2019), Association mapping (Jamali et al., 2017) linkage mapping and phylogenetic analysis (Lakew et al., 2013; Zhang et al., 2014). Among different DNA marker types used in barley, microsatellites have proven to be the markers of choice for genetic diversity studies for this plant species (Wang et al., 2010; Hua et al., 2015; Todorovska et al., 2019).

Although numerous studies have been reported on the diversity of barley using different molecular markers (Al-Hadeithi et al., 2012; Rahimi et al., 2014; Hussain and Adeel, 2017), limited evidence is available about the diversity of the usable barley cultivars in Iraq. To make optimal use of Iraqi germplasm for effective breeding and conservation, evaluation of genetic diversity appears to be essential.

The objective of this research was, therefore, to estimate the extend genetic distance among barley cultivars using SSR markers. It aimed at generating the baseline of useful genetic information to facilitate the germplasm evaluation for the future improvement and conservation of barley genetic resources.

\section{MATERIALS AND METHODS}

Plant Materials: A total of sixteen barley genotypes were used in this study. The genotypes were obtained from different sources of local research centers and international organizations (Table1).

Table 1. Name, pedigree and origin of the sixteen barley genotypes involved in the current study.

\begin{tabular}{lccc}
\hline \multicolumn{1}{c}{ Genotype } & $\begin{array}{c}\text { Row- } \\
\text { type }\end{array}$ & Pedigree & Origin \\
\hline Clipper & 2 row & Clipper/3/JLB37-74 & Agriculture Research Center-Erbil \\
Bohoth H1 & 2 row & - & Agricultural Research Station of \\
Local Abiad & 2 row & - & Bakrajo \\
Sulaimani & 2 row & - & \\
ACSAD 157 & 6 row & OAP-4AP-7L,sel/ICARDA & ICARDA \\
Amal 2 & 6 row & SLB34-65/Arar//Furat-2 & \\
IBA 99 & 6 row & ICB04-0787-0AP-20AP-0AP-0TR-0TR-0AREC & Agricultural Research Station of \\
Furat 2 & 2 row & Mora/NB1054/3/Mola/SHYRI/ABUPO*2/JET/4 & Bakrajo \\
MORA & 2 row & ALELI/CANELA/3/BICHY2000/4/GUENZA & \\
COB & & &
\end{tabular}




\begin{tabular}{lccc}
\hline Canela & 2 row & CANELA/ZEDAR\#2/LIMON/3/MSE & \\
ATACO & 6 row & ATACO/Bermejo/Higo/3/ Cln-B/80 & \\
$\begin{array}{l}\text { ABN-B } \\
\text { Quinn }\end{array}$ & 2 row & KA-B/RAISA/3/ALELI/4/LEMON/5 & CIMMYT \\
Zanbaka & 6 row & Quinn/Aloe/Cardo/3/Ciru & $\begin{array}{c}\text { State Board of Seeds Testing and } \\
\text { Certification. Ministry of Agriculture. } \\
\text { Iraq }\end{array}$ \\
Al-khair & 6 row & Zanbaka/JLB37-064 & $\begin{array}{c}\text { Unit of seed technology / Iraq } \\
\text { State Board of Seeds Testing and } \\
\text { Certification. Ministry of Agriculture. } \\
\text { Iraq }\end{array}$ \\
\hline
\end{tabular}

DNA Isolation: The study was conducted at the Central Laboratory and the Animal Science laboratory of the College of Agricultural Engineering Sciences, University of Sulaimani. DNA was extracted from fresh leaf tissue of the barley genotypes were grown in pots for three weeks, using a modified cetyltrimethylammonium bromide (CTAB) method described by Stein et al. (2001).

After extraction the DNA quality was checked for all the genotypes using 1\% agarose gel. The extracted genomic DNA was kept in the freezer $\left(-20^{\circ} \mathrm{C}\right)$ until used in a polymerase chain reaction. The concentration of each DNA sample was diluted to $20-30 \mathrm{ng} / \mu \mathrm{l}$ by comparing the fluorescence of the genotypes' samples with DNA ladder bands of the same agarose gel under UV fluorescent.

SSR Primers for PCR reaction: Twenty-five PCRbased SSR primers were used in the current study. Twenty-four primers were from the barley genome and selected from previous genetic diversity studies of barley, while one primer was derived from a gene conferring resistance to barley stem gall midge ((Mayetiola hordei), and used in screening the current genotypes. The oligonucleotide primers were ordered from Sinaclon company (Iran). Detailed information about the name and sequences of the primers used is shown in Table 2.

SSR positions were amplified using polymerase chain reaction thermocycler (MultiGene OptiMax Thermal Cycler, Labnet Company). PCR reaction mix was purchased from Sinaclon company (Iran) and contained $10 \times$ assay buffer, $2.5 \mathrm{mM} \mathrm{MgCl} 2,400 \mu \mathrm{M}$ dNTP's and $1 \mathrm{U}$ of Taq DNA Polymerase. Each amplification contained $10 \mu$ of reaction master mix (Sinaclon), 2-3 $\mu$ l of genomic DNA (20-30ng in total), $2 \mu 1$ $(20 \mathrm{ng} / \mu \mathrm{l})$ of each forward and reverse primers, then completed to the final volume of $20 \mu$ l with de-ionized water $\left(\mathrm{dH}_{2} \mathrm{O}\right)$.

Table 2. List of SSR primers, sequences, annealing temperature and their sources used to screen the barley genotypes.

\begin{tabular}{|c|c|c|c|c|c|}
\hline $\begin{array}{l}\text { No } \\
\text {. }\end{array}$ & Primer name & Forward sequence (F: 5'-3') & Reverse sequence (R: 3'-5') & $\begin{array}{l}\text { Annealing } \\
\text { temp. }\left({ }^{\circ} \mathrm{C}\right)\end{array}$ & Sources \\
\hline 1 & 19RTCT & GCATATACAATAGCAAAATTAAGC & GGAGGAGAGGAGAAGAAGAGG & 60 & \\
\hline 2 & 1LATC & CTTGGTGATGTGGTTCTCGTT & CTCACCCAAAAGGAATGGTG & 60 & (Tyrka et al., \\
\hline 3 & 25RACT & CCATACAACTTCAGGTGAGGG & AACTGTTCCAAGGGTCTCGAT & 60 & 2008) \\
\hline 4 & Bmac0134 & CCAACTGAGTCGATCTCG & CTTCGTTGCTTCTCTACCTT & 53 & $\begin{array}{c}\text { (Blori- } \\
\text { Moghadam et } \\
\text { al., 2011) }\end{array}$ \\
\hline 5 & Bmac0163 & TTTCCAACAGAGGGTATTTACG & GCAAAGCCCATGATACATACA & 55 & $\begin{array}{c}\text { (Massadeh et } \\
\text { al., 2015) }\end{array}$ \\
\hline 6 & BMAC624 & AAAAGCATTCAACTTCATAAGA & CAACGCCATCACGTAATA & 50 & $\begin{array}{l}\text { (Naceur } \text { et } \\
\text { al., 2012) }\end{array}$ \\
\hline 7 & EBmac701 & ATGATGAGAACTCTTCACCC & TGGCACTAAAGCAAAAGAC & 55 & $\begin{array}{c}\text { (Oliver et al., } \\
\text { 2009) }\end{array}$ \\
\hline 8 & GB318 & CGGCTCAAGGTCTCTTCTTC & TATCTCAGATGCCCCTTTCC & 62 & \\
\hline 9 & GB357 & GCTCCAGGGCTCCTCTTC & AGCTCTCTCTGCACGTCCTT & 60 & \\
\hline 10 & GB371 & CACCAAGTTCACCTCGTCCT & TTATTCAGGCAGCACCATTG & 62 & (Raoudha $e t$ \\
\hline 11 & GB384 & CTGCTGTTGCTGTTGTCGTT & ACTCGGGGTCCTTGAGTATG & 60 & al., 2007) \\
\hline 12 & GB391 & AGCTCCTTTCCTCCСТTCC & CCAACATCTCCTCCTCCTGA & 60 & \\
\hline 13 & GB402 & CAAGCAAGCAAGCAGAGAGA & AACTTGTGGCTCTGCGACTC & 60 & \\
\hline 14 & HVCMA & GCCTCGGTTTGGACATATAAAG & GTAAAGCAAATGTTGAGCAACG & 55 & $\begin{array}{c}\text { (Blori- } \\
\text { Moghadam et } \\
\text { al., 2011) }\end{array}$ \\
\hline
\end{tabular}




\begin{tabular}{|c|c|c|c|c|c|}
\hline 15 & MAG13 & AAGGGGAATCAAAATGGGAG & TCGAATAGGTCTCCGAAGAAA & 56 & \\
\hline 16 & MAG149 & CAAGCCAACAGGGTAGTC & ATTCGGTTTCTAGAGGAAGAA & 56 & (Raoudha et \\
\hline 17 & MAG210 & ACCTACAGTTCAATAGCTAGTACC & GCACAAAACGATTACATCATA & 50 & \\
\hline 18 & MS02 & AGAGTAGTGGAAAGAAGTT & TGGTAGTGAGATGAGGTGAC & 52 & (Raoudha et \\
\hline 19 & MS1 & CTGACCCTTTGCTTAACATGC & TCAGCGTGACAAACAATAAAGG & 52 & al., 2007) \\
\hline 20 & QLB1 & CCAAGAACAACACAAGGGAAA & CCCAACAACTTGTGCCTAAAA & 60 & $\begin{array}{c}\text { (Tyrka et al., } \\
\text { 2008) }\end{array}$ \\
\hline 21 & V13GEIII & AGGAACCCTACGCCTTACGAG & AGGACCGAGAGTGGTGGTGG & 54 & \\
\hline 22 & VB23D & GGTAGCAGACCGATGGATGT & ACTCTGACACGCACGAACAC & 62 & (Raoudha et \\
\hline 23 & VGLUEND & TTCGCCTCCATCCCACAAAG & GCAGAACGAAAGCGACATGC & 62 & al., 2007) \\
\hline 24 & VITR1 & CCACTTGCCAAACACTAGACCC & TTCATGCAGATCGGGCCAC & 55 & \\
\hline 25 & MhA6* & AATTATGTAAACCGAACCGAAC & CGAATCCAAAGAGGAAGTGG & 54 & $\begin{array}{l}\text { (Mezghani- } \\
\text { Khemakhem } \\
\text { et al., 2012) }\end{array}$ \\
\hline
\end{tabular}

*; from Barley Stem Gall Midge (Mayetiola hordei).

The PCR program was set up for one initial denaturation cycle at $94^{\circ} \mathrm{C}$ for 4 minutes, followed by 40 cycles of 60 seconds at $94^{\circ} \mathrm{C}$, and then 60 seconds at the appropriate annealing temperature (adjusted previously between $50-65^{\circ} \mathrm{C}$ ), followed by 2 minutes of extension step at $72^{\circ} \mathrm{C}$. Termination stage was set up with a final extension of $72^{\circ} \mathrm{C}$ for 10 minutes. From each DNA sample, a total of $10 \mu \mathrm{l}$ aliquot of the PCR product was mixed with $3 \mu \mathrm{l}$ of electrophoresis $6 \mathrm{x}$ loading buffer. Then, the samples were loaded onto $1 \%$ agarose gel in TBE buffer (1\%). The amount of $3 \mu$ l ethidium bromide $(0.5 \mu \mathrm{g} / \mathrm{mL})$ was added to the gel when cooled down, and mixed before pouring into the tray. After loading the samples, the gels were run on $80 \mathrm{~V}$ for 120 minutes. The fragments were separated by electrophoresis and visualized under UV Transilluminators.

Data analysis: The amplified fragments of the primers' alleles were scored as " 1 " and " 0 " for the presence and absence of alleles, respectively. Gene diversity and polymorphic information content were estimated on the basis of frequencies of identified alleles. The polymorphism percentage was calculated for all polymorphic SSR markers according to the method of Blair et al. (1999).

Polymorphism

$\frac{\text { total number of bands - number of monomorphic bands }}{\text { total number of bands }}$ X100

The polymorphic information content (PIC) of each microsatellite locus was evaluated through allelic frequency (Anderson et al., 1993):

$$
\mathrm{PIC}=1-\sum_{i=1}^{k} p i^{2}
$$

Where $k$ is the total number of alleles detected for a microsatellite and $\mathrm{p} i$ the frequency of the $i$ th allele in germplasm.

Binary matrix data was applied for the calculation of Jaccard's similarity coefficient using the XLSTAT 2017 software. Jaccard's coefficient was converted to dissimilarity matrix to create a dendrogram using the unweighted pair-group method with arithmetic averages (UPGMA). To determine the relationship between different genotypes, the principal component analysis (PCA) was conducted using the same software. DARwin software (version 6) was used to analyze Principal Coordinate Analysis and bootstrap values at the nodes of dendrogram after 1000 permutation to estimate the reliability of tree topology.

\section{RESULTS AND DISCUSSION}

Due to limited genetic variation among modern crop species, efficient use of the available genetic variation of local and non-adapted modern cultivars is necessary for germplasm maintenance, and for improving different crops (Russell et al., 1997; Tanksley and McCouch, 1997; Frankham et al., 2010; Chen et al., 2020), since the development of new improved genotypes requires the exploration and characterization of genetic diversity in available germplasm (Elakhdar et al., 2018). This diversity study may improve the efficiency of germplasm management operations, preventing the loss of allelic diversity through random genetic drift (Russell et al., 1997; Frankham et al., 2010).

Studying genetic distance at molecular level in barley germplasm is an important prerequisite for maximum exploitation of barley genotypes in breeding programs and also for the conservation of barley genetic diversity (Malysheva-Otto et al., 2006). Since Iraq is part of Fertile Crescent which is the center of barley domestication, exploring the local germplasm with the elite varieties could maximize the extent of genetic diversity in breeding programs to develop new cultivars with higher adapted to local biotic and biotic stress.

Due to the advantages of microsatellite markers over other classes of molecular markers, they were employed to study the genetic diversity of the available barley genotypes (including the domestics and introduced genotypes). The SSRs used in the current investigation are distributed across all seven barley chromosomes and generated clear patterns of polymorphism. A total of 25 
SSR markers were polymorphic and able to detect 94 alleles when applied to the 16 barley genotypes,

In genetic diversity analysis, the number of alleles per locus is counted to be a significant indicator for diversity and it depends on the genotypes, the loci investigated and the marker type (Pasam et al., 2014) . In the current study, about 2-8 alleles were detected per a locus with an average of 3.76 alleles (Table 3 ).

Table 3. Amplification information, chromosomal location, polymorphism, alleles and gene diversity, and PIC values for 25 SSR primers applied on 16 barley genotypes.

\begin{tabular}{|c|c|c|c|c|c|c|c|c|c|}
\hline No. & Primer & Chr. No. & $\begin{array}{l}\text { Total } \\
\text { allele }\end{array}$ & $\begin{array}{l}\text { Polymorphic } \\
\text { allele }\end{array}$ & $\begin{array}{c}\text { Polymorphism } \\
\%\end{array}$ & $\begin{array}{c}\text { Size of } \\
\text { amplified } \\
\text { bands }\end{array}$ & $\begin{array}{c}\text { Major } \\
\text { allele } \\
\text { frequency }\end{array}$ & $\begin{array}{c}\text { Gene } \\
\text { Diversity }\end{array}$ & PIC \\
\hline 1 & 19RTCT & $3 \mathrm{H}$ & 6 & 1 & 16.667 & $80-650$ & 0.750 & 0.375 & 0.305 \\
\hline 2 & 1LATC & $3 \mathrm{H}$ & 2 & 2 & 100 & $160-180$ & 0.500 & 0.555 & 0.456 \\
\hline 3 & 25RACT & $3 \mathrm{H}$ & 2 & 2 & 100 & $190-210$ & 0.813 & 0.320 & 0.294 \\
\hline 4 & Bmac0134 & $2(2 \mathrm{H})$ & 2 & 2 & 100 & $100-140$ & 0.438 & 0.672 & 0.612 \\
\hline 5 & Bmac0163 & $5 \mathrm{H}$ & 2 & 2 & 100 & $150-160$ & 0.688 & 0.461 & 0.398 \\
\hline 6 & Bmac624 & $6(6 \mathrm{H})$ & 3 & 3 & 100 & $120-150$ & 0.688 & 0.492 & 0.458 \\
\hline 7 & EBmac0701 & $4 \mathrm{H}$ & 2 & 2 & 100 & $100-150$ & 0.750 & 0.398 & 0.354 \\
\hline 8 & GB318 & $7(5 \mathrm{H})$ & 4 & 4 & 100 & $150-600$ & 0.438 & 0.695 & 0.649 \\
\hline 9 & GB357 & $7(5 \mathrm{H})$ & 6 & 6 & 100 & $220-1200$ & 0.188 & 0.883 & 0.871 \\
\hline 10 & GB371 & $6(6 \mathrm{H})$ & 8 & 8 & 100 & $150-1200$ & 0.375 & 0.742 & 0.701 \\
\hline 11 & GB384 & $5 \mathrm{H}$ & 2 & 2 & 100 & $190-220$ & 0.625 & 0.469 & 0.359 \\
\hline 12 & GB391 & $2 \mathrm{H}$ & 3 & 3 & 100 & $510-550$ & 0.750 & 0.414 & 0.387 \\
\hline 13 & GB402 & $5(1 \mathrm{H})$ & 2 & 1 & 50 & $80-250$ & 0.625 & 0.469 & 0.359 \\
\hline 14 & HVCMA & $7 \mathrm{H}$ & 3 & 3 & 100 & $150-300$ & 0.500 & 0.648 & 0.592 \\
\hline 15 & MAG13 & $3(3 \mathrm{H})$ & 3 & 3 & 100 & $150-190$ & 0.438 & 0.602 & 0.516 \\
\hline 16 & MAG149 & $5(1 \mathrm{H})$ & 8 & 8 & 100 & $150-700$ & 0.313 & 0.828 & 0.810 \\
\hline 17 & MAG210 & $6(6 \mathrm{H})$ & 2 & 1 & 50 & $120-170$ & 0.813 & 0.305 & 0.258 \\
\hline 18 & MS02 & $7(5 \mathrm{H})$ & 5 & 1 & 20 & $150-1200$ & 0.688 & 0.430 & 0.337 \\
\hline 19 & MS1 & $5 \mathrm{H}$ & 2 & 2 & 100 & $120-150$ & 0.500 & 0.500 & 0.375 \\
\hline 20 & QLB1 & $5 \mathrm{H}$ & 4 & 4 & 100 & $250-900$ & 0.438 & 0.703 & 0.657 \\
\hline 21 & V13GEIII & $3(3 \mathrm{H})$ & 3 & 3 & 100 & $100-500$ & 0.625 & 0.563 & 0.524 \\
\hline 22 & VB23D & $4(4 \mathrm{H})$ & 8 & 7 & 87.500 & $100-1200$ & 0.125 & 0.898 & 0.889 \\
\hline 23 & VGLUEND & $5(1 \mathrm{H})$ & 2 & 1 & 50 & $280-350$ & 0.688 & 0.430 & 0.337 \\
\hline 24 & VITR1 & $3(3 \mathrm{H})$ & 6 & 3 & 50 & $210-550$ & 0.438 & 0.695 & 0.645 \\
\hline \multirow[t]{3}{*}{25} & MhA6 & - & 4 & 2 & 50 & $150-1000$ & 0.375 & 0.727 & 0.682 \\
\hline & Total & & 94 & 76 & 80.851 & & & & \\
\hline & Average & & 3.760 & 3.04 & & & 0.543 & 0.571 & 0.513 \\
\hline
\end{tabular}

This result is greater than $2.6 /$ locus reported by Elakhdar et al. (2016b), but lesser than 4 alleles/locus that found by Elakhdar et al. (2018), and 6.29 alleles/locus found by Todorovska et al. (2019). Size of amplified bands (from 80 to $1200 \mathrm{bp}$ ) was estimated by comparing the PCR products with the known size of DNA fragments ladder. SSR alleles were manually scored as 1 or 0 (the presence and absence, respectively) only for clear bands. Out of this number, a total of 76 alleles were polymorphic and had an average of 3.04 alleles/primer. This result was higher than the average of 2.4 alleles/locus obtained by Wang et al. (2010) in a collection of 40 different genotypes from different origins. Our results indicating high genetic distance between the barley genotypes under study. Polymorphic alleles were ranged from 1 to 8 alleles for different primers used. A lower average was also (1.6 alleles per locus) obtained by Al-Hadeithi (2016) who used six SSR markers to screen nine barley varieties including IPA99 and Al-khair.

Primers GB371 and MAG149 had the highest polymorphic value of eight alleles/primer. Polymorphism varied for different markers, ranged from $16.667 \%$ to $100 \%$, however the majority of primers were highly polymorphic. This divergence may be due to the diversification of varieties and the choice of SSR primers with high allele number per locus, from previous investigations of barley genotypes (Table 2). The considerable number of the detectable and polymorphic fragments might be expected to the number of GC of the primers utilized in this research. The distinction in the number of bands amplified by different primers is influenced by several factors such as primer sequence and 
less number of annealing sites in the genome (Tahir, 2014).

The amplified alleles had different sizes, ranging from $80 \mathrm{bp}-1200 \mathrm{bp}$. The highest major allele frequency (0.813) was obtained from SSR markers 25RACT and MAG210, while the minimum value of 0.125 was obtained from SSR marker VB23D. Gene diversity was expressed reversely to the allele frequency. It means VB23D marker is more specified with common alleles rather than rare alleles in the population of barley under study and the population has not reached the allelic saturation yet (Greenbaum et al., 2014). High values of gene diversity and PIC rate for this marker indicating the informative power of VB23D marker for studying the genetic diversity and population structure of barley crop. Same pattern was realized for the gene diversity of this DNA marker, giving less differentiation power (Gougerdchi et al., 2014). Genetic diversity was estimated, using SSR markers for barley genotypes. The average gene diversity for the entire samples set was found to be 0.571 , with a range of 0.305 for marker MAG210 to 0.828 for MAG149 (Table 3). The broad range of gene diversity among barley genotypes, based on the SSR markers used, might be a source of the different genetic resources in barley, such as landraces, advanced breeding lines, cultivars. PIC of SSR markers is able to discriminate genotypes and evaluate the level of gene variation, which mostly depend on the allelic diversity. PIC values of $>0.889$ and $<0.258$ here indicate the loci with high and low diversity, respectively. Number of genotypes and the efficiency of markers for detecting alleles are relatively determine the PIC values. The PIC mean value was 0.513 which slightly higher than PIC value of 0.36 by Elakhdar et al. (2016b), and lower than PIC value of 0.54 by Pasam et al. (2014).

Transferability of SSR markers has been reported previously across species and genera of the insects (Weng et al., 2007) and plant species themselves (Ahmad, 2013), while according to our knowledge no transferable common marker has been realized between insect and plant species before, since we have assured non contamination of barley genotypes with any genomic DNA of Mayetiola hordei. This attempt had a reasonable result of amplification and polymorphism detection in the current study by using the SSR primer (MhA6) from barley stem gall midge (Mayetiola hordei). Four alleles were amplified having $50 \%$ of polymorphism among the barley genotypes.

The marker gave reasonable gene diversity and PIC values of 0.727 and 0.682 , respectively. This compatibility between the host and its pathogen alleles might be referring to the emphasized relation through gene-for-gene interaction to shape the mechanism of plant immune system against its pathogen (Chisholm et al., 2006)
Principal companion analysis was performed to estimate the relative importance and contribution of each genotype to the total variance and illustrate the genetic diversity among the 16 genotypes (Table 3 ).

\section{Table 3. First and second components scores of the 16} barley genotypes and their Egin-values.

\begin{tabular}{lcc}
\hline \multicolumn{1}{c}{ Component } & PC1 & PC2 \\
\hline Clipper & 0.015 & 0.079 \\
Bohoth H1 & 0.155 & 0.001 \\
Local Abiad Sulaimani & 0.127 & $\mathbf{0 . 3 6 4}$ \\
ACSAD 157 & 0.129 & 0.012 \\
Amal 2 & 0.000 & $\mathbf{0 . 3 8 4}$ \\
IBA 99 & 0.017 & 0.047 \\
Furat 2 & 0.002 & 0.170 \\
MORA & 0.049 & 0.015 \\
COB & 0.038 & 0.028 \\
Canela & $\mathbf{0 . 6 3 0}$ & 0.069 \\
ATACO & $\mathbf{0 . 6 6 1}$ & 0.058 \\
ABN-B & 0.001 & 0.200 \\
Quinn & 0.075 & 0.016 \\
Zanbaka & 0.174 & $\mathbf{0 . 2 6 4}$ \\
Al-khair & 0.132 & $\mathbf{0 . 2 1 3}$ \\
Arta/3/Avar & 0.140 & $\mathbf{0 . 3 4 7}$ \\
Eigenvalue & 14.090 & 10.062 \\
Variability (\%) & 18.540 & 13.240 \\
\hline Na: Th
\end{tabular}

Note: The important contributions are represented in bold.

The first two Principal Components (PCs) with Eigen-value $>10$ accounted for $31.78 \%$ of the total genetic variation (Table 3 and Figure 1), while the others, with the Eigen-values above one decimal number from PC3-PC15, were explained the remaining percent of total genetic variation. The score of the first component (PC1) was high and significant for ATACO and Canela giving the squared value of 0.661 and 0.630 , respectively. While numerous genotypes showed the highest and significant value of 0.384 for Amal2 in PC2. The significance of the components values here shows the importance of the above genotypes as principal discriminatory factors for the barley genotypes under study.

A principal component analysis was performed to interpret the distance between the barley genotypes, as the first and second principal components (PC1 and $\mathrm{PC} 2)$ were used to express the biplot diagram. The Scree plot indicates the most of the variation is derived the first and second factors (F1 and F2) in the Eigen-value of the genotypes data. The results obtained from Biplot-PCA indicated the presence of high genetic variations among barley genotypes based on SSR marker data (Figure 1). ATACO and Canela were also found to be very distanced genetically from other genotypes, followed by Local Abiad Sulaimani and Amal2 that distanced from the rest of genotypes under study. 
Barley breeding institutes and research centers should take consideration of the necessity for the collection, conservation, and utilization of the local cultivars and landraces. The importance of this action has been emphasized in this investigation by giving a reasonable extension to barley gene pool via the contribution of indigenous genetic resources such as Local Abiad Sulaimani. The other 12 barley genotypes were dispersed on the plot with less genetic distance. The presence of common ancestors might be the reason for the close distance between these genotypes, framing them within a group corporation (Mohamed and Adel, 2012).

Presence of high levels of genetic diversity among the barley genotypes lead to the allelic richness that may represent their characteristics in the population. This level of diversity might be due to their geographical pattern, different pedigree, characteristics and growth behavior.

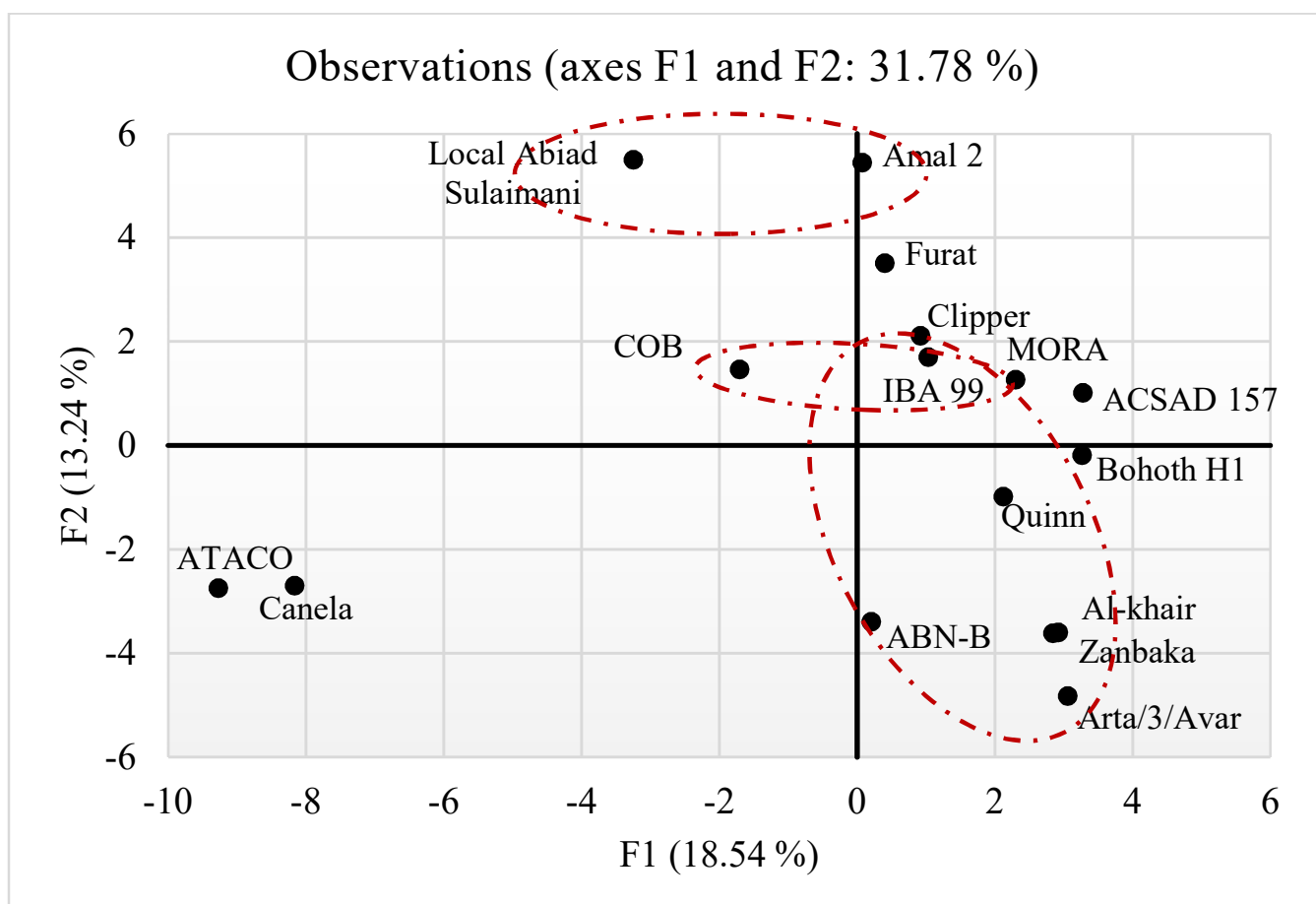

Figure 1. Biplot diagram of principal component analysis of the first and second components for the distribution of 16 barley genotypes, based on SSR DNA marker

Agglomerative Hierarchical Clustering Using SSR Marker Data: Pairwise comparisons were made between all genotypes and the average dissimilarity values were calculated based on the microsatellite-derived data. The distance between all 16 barley genotypes was evaluated using the alleles derived from applying 25 SSR primers. All 76 polymorphic alleles across the genotypes were utilized to evaluate the relationship between the genotypes. Dissimilarity values were ranged from 0.333 (between Zanbaka and Arta/3/Avar) to 0.849 (between ACSAD 157 and ATACO), as given in Table 4. This range of dissimilarity indicated the presence of reasonable variability among the genotypes under study.
Hybridization program might be reasonable if conducted between ACSAD 157 and ATACO, due to the high dissimilarity observed to obtain higher heterosis value for important traits, and also mitigating the acceleration of extinction of primitive and adaptive genes among the studied genotypes (Govindaraj et al., 2015). The calculated small distances between Zanbaka and Arta/3/Avar could have corresponded to their origination from a common ancestor or some genetic materials might be exchanged among parental roots of these genotypes, making them be incorporated in one main group. 
Table 4. Dissimilarity matrix among the 16 barley genotypes based on SSR marker data, following Jaccard's coefficient analysis.

\begin{tabular}{|c|c|c|c|c|c|c|c|c|c|c|c|c|c|c|c|c|}
\hline Genotype & V1 & $\mathrm{V2}$ & V3 & V4 & V5 & V6 & V7 & V8 & V9 & V10 & V11 & V12 & V13 & V14 & V15 & V16 \\
\hline V1 & 0.000 & & & & & & & & & & & & & & & \\
\hline $\mathrm{V} 2$ & 0.526 & 0.000 & & & & & & & & & & & & & & \\
\hline V3 & 0.481 & 0.582 & 0.000 & & & & & & & & & & & & & \\
\hline V4 & 0.404 & 0.451 & 0.625 & 0.000 & & & & & & & & & & & & \\
\hline V5 & 0.455 & 0.554 & 0.451 & 0.545 & 0.000 & & & & & & & & & & & \\
\hline V6 & 0.455 & 0.412 & 0.451 & 0.431 & 0.481 & 0.000 & & & & & & & & & & \\
\hline V7 & 0.554 & 0.519 & 0.558 & 0.480 & 0.556 & 0.471 & 0.000 & & & & & & & & & \\
\hline V8 & 0.492 & 0.396 & 0.569 & 0.500 & 0.491 & 0.491 & 0.453 & 0.000 & & & & & & & & \\
\hline V9 & 0.453 & 0.582 & 0.538 & 0.600 & 0.509 & 0.589 & 0.558 & 0.373 & 0.000 & & & & & & & \\
\hline V10 & 0.623 & 0.768 & 0.633 & 0.741 & 0.727 & 0.679 & 0.755 & 0.630 & 0.574 & 0.000 & & & & & & \\
\hline V11 & 0.755 & 0.808 & 0.750 & 0.849 & 0.811 & 0.740 & 0.820 & 0.782 & 0.723 & 0.622 & 0.000 & & & & & \\
\hline V12 & 0.607 & 0.490 & 0.714 & 0.569 & 0.636 & 0.611 & 0.608 & 0.451 & 0.588 & 0.600 & 0.756 & 0.000 & & & & \\
\hline V13 & 0.500 & 0.491 & 0.632 & 0.638 & 0.527 & 0.554 & 0.547 & 0.455 & 0.500 & 0.698 & 0.808 & 0.520 & 0.000 & & & \\
\hline V14 & 0.518 & 0.420 & 0.649 & 0.500 & 0.621 & 0.462 & 0.593 & 0.444 & 0.490 & 0.667 & 0.827 & 0.479 & 0.420 & 0.000 & & \\
\hline V15 & 0.444 & 0.545 & 0.632 & 0.509 & 0.627 & 0.412 & 0.649 & 0.534 & 0.582 & 0.698 & 0.784 & 0.549 & 0.431 & 0.354 & 0.000 & \\
\hline V16 & 0.519 & 0.449 & 0.702 & 0.500 & 0.672 & 0.547 & 0.648 & 0.500 & 0.577 & 0.725 & 0.816 & 0.478 & 0.480 & 0.333 & 0.348 & 0.000 \\
\hline
\end{tabular}

Note: V1: Clipper, V2: Bohoth H1, V3: Local Abiad Sulaimani, V4: ACSAD 157, V5: Amal2, V6: IBA 99, V7: Furat 2, V8: MORA, V9: COB, V10: Canela, V11: ATACO,

V12: ABN, V13: Quinn, V14: Zanbaka, V15: Al-khair and V16: Arta/3/Avar 
Success in breeding purposes, utilization and effective conservation of genetic resources depends on correct estimations of these parameters. To avoid the potential risks associated with bottlenecking the genetic diversity in barley, the adoption of genotypes with wide diversities have to be involved as parental lines in barley improving programs.

The amplified loci arranged in matrix data were utilized to evaluate the relationship between the genotypes under study by creating a dendrogram using the Jaccard's similarity coefficient. All the 16 genotypes were discriminated into seven main clusters at 0.505 threshold value of dissimilarity (Figure 2). The available genetic distance among the barley genotypes, based on SSR data, shows a wide distribution tendency of the barley genotypes in this region.

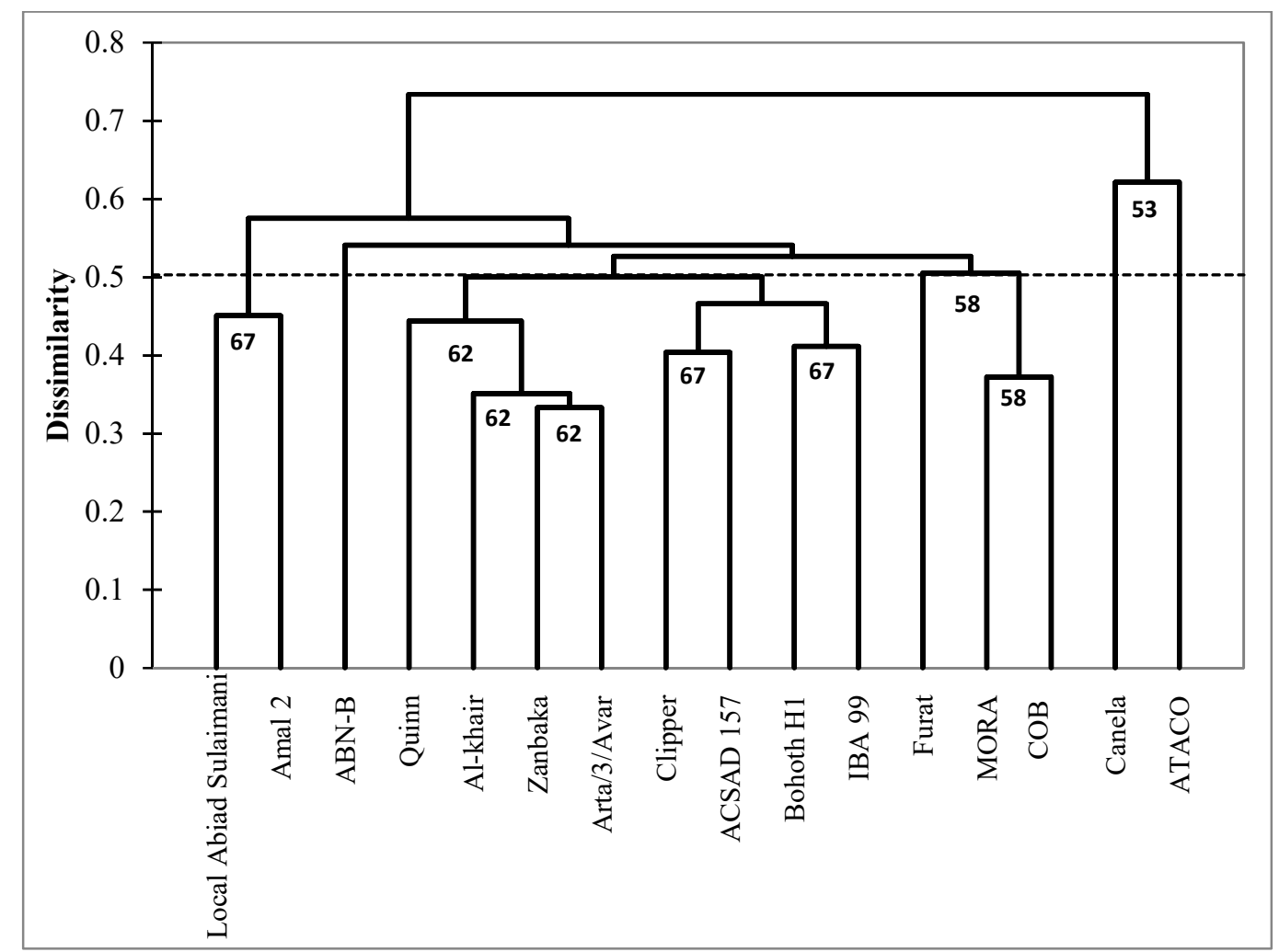

Figure 2. Dendrogram generated using Unweighted pair-group average of Jaccard's coefficient analysis dissimilarity, showing the distance between the barley genotypes using SSR marker data. Dissimilarity values are present at left side of the dendrogram. Bootstrap values are shown at the nodes

Despite the presence of higher genetic distance within the classes $(78.60 \%)$ compared to the distances between the classes $(21.4 \%)$, agglomeration method of unweighted pair-group average was able to cluster the genotypes into seven groups. The first main cluster was comprised of eight genotypes (Clipper, Bohoth H1, ACSAD 157, IPA99, Quinn, Zanbaka, Al-khair and Arta/3/Avar), having 12.232 within-class variances. However, this cluster has been split into two main subgroups. The genotypes Quinn, Zanbaka, Al-khair and Arta/3/Avar were incorporated into the first sub-group while the rest genotype of this cluster incorporated into the second sub-group. Same results of clustering Quinn, Zanbaka, Al-khair and Arta/3/Avar genotypes in the first sub-group has been obtained by Tahir (2014) using RAPD DNA markers, confirming their strong genetic relationship compared to other genotypes. Care should be taken in involving these genotypes into hybridization programs, trying to include those clustered separately.

The second cluster included two genotypes of Local Abiad Sulaimani and Amal2. They implicate narrow genetic diversity with each other. Exchanged genetic material between these two genotypes might be occurred through previous breeding programs in Iraq, also they could be descent from the same origin (Hamza et al., 2004).

No large differences in genetic diversity between the clustered groups have extinguished based on row-types in the current study, however different grouping structures corresponding to row-type been reported earlier in of in American barley germplasm (Hamblin et al., 2010). However two-rowed barley are 
specified with the dried or rainfed condition while sixrowed are more specified with the irrigated regions in Iraq, admixed ancestry of both barley types has been realized in the analysis of the genotypes under study. In order to assess the clustering of barley accessions based on SSR polymorphism, we conducted a principal coordinate analysis (PCoA). The scatter plots for the two first axes showed that accessions formed two main principal groups (Figure 3). The first group includes nine barley genotypes (Clipper, Bohoth H1, ACSAD 157, IPA99, Quinn, Zanbaka, MORA, Al-khair and Arta/3/Avar), while the second is only two barley involved (Amal2 and Local Abid Sulaimani). PCoA results are in agreement with the UPGMA and PCA analysis in terms of clustering and genotypes involved.

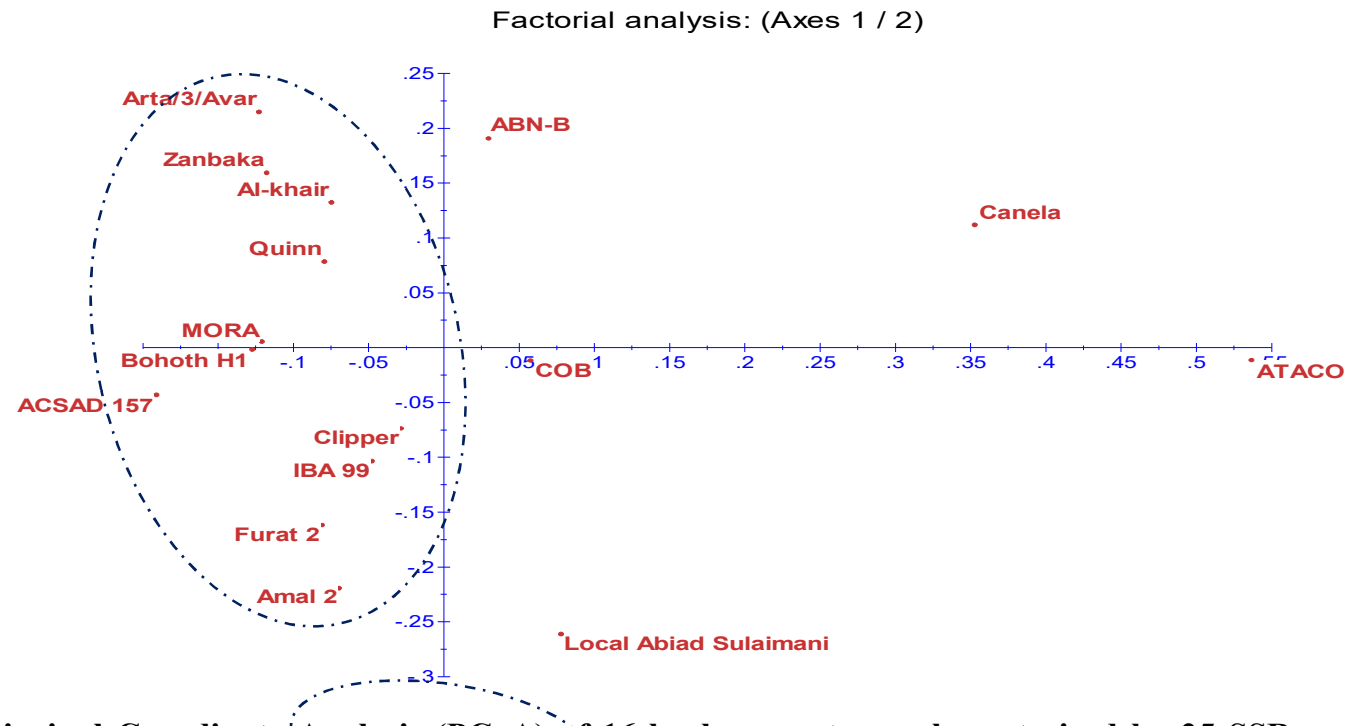

Figure 3. Principal Coordinate Analysis (PCoA) of 16 barley genotypes characterized by 25 SSR marker. Two main groups were identified, while the others were stuttered across the plot.

However the characterizations in barley genotypes are largely focused on the distributions of diversity based on eco-geographical distribution (Yahiaoui et al., 2008; Hübner et al., 2009; Russell et al., 2016), this characterization is not emphasized directly on the current barley genotypes, behaving pattern for genotypes of different geographical location are not always different genetically (Evanno et al., 2005; Yahiaoui et al., 2008). No distinct regional grouping patterns of barley genotypes from same or adjacent regions appeared in same groups clusters by Yadav et al. (2018) and Mekonnon et al. (2015) based on agronomic characters.

While posing reasonable distance between this group and the others (having 2.398 value as a minimum distance to dendrogram centroid), will assure a reasonable contribution of these two genotypes as a potential gene source to improve the adaptation of barley for the future hybridization program in the region. The fourth cluster also had involved both MORA and GOB with less within-class distance (9.5). Other genotypes of Furat2, Canela, ATACO and ABN-B were individually distributed on clusters 3,5,6 and 7, respectively. The results here indicate the efficiency of SSR markers as powerful tools in detecting co-dominant single locus to examine the genetic relationship between barley genotypes. Bootstrap values were ranged from 0.53-0.67, however the values are not very high, they may support the relations identified between the studied genotypes. It has been indicated that over $30 \%$ of bootstrap value suggests good robustness of the dendrogram (Kahodariya et al., 2015). The genetic relationship of the barley genotypes was clearly identified by cluster analysis identifying the potential and ability of microsatellite markers for genome analysis in barley, however monitoring the extent of genetic diversity of the barley genotypes with higher precision can be achieved by using more DNA markers. Both PCA and Dendrogram analysis methods showed a high degree of variation among analyzed genotypes. The results would be valuable for the breeders in such a way that the most promising genotypes in the population maybe selected from different clusters for crop improvement. Estimating the genetic diversity at the DNA level within the current barley genotypes could provide a clear figure of the genetic diversity of this crop in Kurdistan-Iraq to exploit parent selection, the identification of sub-genomic regions for the targeted increase in variability, and identification of new distinct gene pools in barley to be involved in the future improvement programs of this crop. 
Conclusion: Molecular diversity analysis with SSR markers was used successfully as a tool for the genetic diversity of barley. The current results demonstrate that the data generated from a set of 25 SSR markers were highly informative. They were able to distinguish all 16 genotypes successfully with 76 polymorphic alleles (3.04 alleles/primer in average), however, further SSR markers combining with different DNA based techniques are more valuable for prominent discrimination among the barley genotypes. The transferability of MhA6 as a common marker from Stem Gall Midge Mayetiola hordei to Hordeum was identified. The markers identified with high polymorphism allele diversity and PIC will be useful for the conservation of poorly characterized barley genetic resources and determining the extent of the available barley gene pool. Results of this diversity analysis with PCA, AHC and PCoA will assist the potential parent selection to be used in improving programs and germplasm management of barley crop.

The present diversity available in barley genotypes is the collection from local and international researched centers for the current exotic and indigenous germplasm available in the region. This finding would be new sources of variation for beneficial traits such as early maturity, resistance to biotic and abiotic stresses, to meet the instant challenges of global food security. In the upcoming period, there is a need to further strengthen the genetic bases for barley germplasm to assist varietal development in the future.

Acknowledgments: The authors are grateful to the Central laboratory and Animal Science Department at the College of Agricultural Engineering Sciences, University of Sulaimani, Kurdistan-Iraq for their permission to work in their laboratories. Many thanks also to Sulaimani Agriculture Research Center in Sulaimani to provide us with the seed of some barley genotypes.

\section{REFERENCES}

Ahmad, A., Wang, J.-D., Pan, Y.-B., Sharif, R., Gao, S.J., 2018. Development and use of simple sequence repeats (SSRs) markers for sugarcane breeding and genetic studies. Agronomy 8, 1-19.

Ahmad, N.S., 2013. Genetic analysis of plant morphology in bambara groundnut (Vigna subterranea (L.) Verdc.), School of Biosciences, University of Nottingham, Nottingham, p. 328.

Al-Hadeithi, Z.S., 2016. Detection of Genetic Polymorphism in Iraqi Barley using SSR-PCR Analysis. Iraqi J. Science 57, 1158-1164.

Al-Hadeithi, Z.S., Al-Kazaz, A.K.A., Al-Obaidi, B.K., 2012. Genetic Diversity and Relationships Among Iraqi Barley Cultivars Using RAPDPCR Technique. Iraqi J. Agricultural Science 43, 117-124.
Amezrou, R., Gyawali, S., Belqadi, L., Chao, S., Arbaoui, M., Mamidi, S., Rehman, S., Sreedasyam, A., Verma, R.P.S., 2018. Molecular and phenotypic diversity of ICARDA spring barley (Hordeum vulgare L.) collection. Genetic resources and crop evolution 65, 255 269.

Anderson, J.A., Churchill, G., Autrique, J., Tanksley, S., Sorrells, M., 1993. Optimizing parental selection for genetic linkage maps. Genome 36, 181-186.

Arya, L., Verma, M., Singh, S., Verma, R., 2019. Spatiotemporal genetic diversity in Indian barley (Hordeum vulgare L.) varieties based on SSR markers. Indian J. Experimental Biology 57, 545-552.

Baum, M., Grando, S., Ceccarelli, S., Backes, G., Jahoor, A., 2004. Localization of quantitative trait loci for dryland characters in barley by linkage mapping, Challenges and Strategies of Dryland Agriculture, USA, pp. 191-202.

Blair, M., Panaud, O., McCouch, S., 1999. Inter-simple sequence repeat (ISSR) amplification for analysis of microsatellite motif frequency and fingerprinting in rice (Oryza sativa L.). Theoretical and Applied Genetics 98, 780-792.

Blori-Moghadam, M.R., Safarnejad, A., Kazemitabar, S.K., 2011. Genetic diversity assessment in several barley (Hordeum vulgare L.) cultivars using microsatellite markers. Notulae Scientia Biologicae 3, 140.

Bosch, T.C., Adamska, M., Augustin, R., Domazet-Loso, T., Foret, S., Fraune, S., Funayama, N., Grasis, J., Hamada, M., Hatta, M., 2014. How do environmental factors influence life cycles and development? An experimental framework for early-diverging metazoans. Bioessays 36, 1185 1194.

Bothmer, R.V., Badent, C., Jacobsen, N.H., 2009. Hordeum, in: Anderton, L.K., Barkworth, M.E. (Eds.), Grasses of the Intermountain Region, Utah State University, Logan, p. 599.

Carter, A.Y., Hawes, M.C., Ottman, M.J., 2019. DroughtTolerant Barley: I. Field Observations of Growth and Development. Agronomy 9, 221.

Chaudhary, B., 2013. Plant domestication and resistance to herbivory. International J. Plant Genomics 2013, 1-14.

Chen, C., Chu, Y., Ding, C., Su, X., Huang, Q., 2020. Genetic diversity and population structure of black cottonwood (Populus deltoides) revealed using simple sequence repeat markers. BMC genetics 21, 1-12.

Chisholm, S.T., Coaker, G., Day, B., Staskawicz, B.J., 2006. Host-microbe interactions: shaping the evolution of the plant immune response. Cell $124,803-814$. 
Curto, M., Winter, S., Seiter, A., Schmid, L., Scheicher, K., Barthel, L.M., Plass, J., Meimberg, H., 2019. Application of a SSR-GBS marker system on investigation of European Hedgehog species and their hybrid zone dynamics. Ecology and evolution 9, 2814-2832.

Dai, F., Nevo, E., Wu, D., Comadran, J., Zhou, M., Qiu, L., Chen, Z., Beiles, A., Chen, G., Zhang, G., 2012. Tibet is one of the centers of domestication of cultivated barley. Proceedings of the National Academy of Sciences 109, 16969-16973.

Dawson, I.K., Russell, J., Powell, W., Steffenson, B., Thomas, W.T., Waugh, R., 2015. Barley: a translational model for adaptation to climate change. New Phytologist 206, 913-931.

Duvick, D.N., 2005. The contribution of breeding to yield advances in maize (Zea mays L.). Advances in agronomy 86, 83-145.

Elakhdar, A., El-Sattar, M.A., Amer, K., Kumamaru, T., 2016a. Genetic diversity and association analysis among Egyptian barley ('Hordeum vulgare'L.) genotypes with different adaptations to saline conditions analyzed by SSR markers. Australian J. Crop Science 10, 637-645.

Elakhdar, A., EL-Sattar, M.A., Amer, K., Rady, A., Kumamaru, T., 2016b. Population structure and marker-trait association of salt tolerance in barley (Hordeum vulgare L.). Comptes rendus biologies 339, 454-461.

Elakhdar, A., Kumamaru, T., Qualset, C.O., Brueggeman, R.S., Amer, K., Capo-chichi, L., 2018. Assessment of genetic diversity in Egyptian barley (Hordeum vulgare L.) genotypes using SSR and SNP markers. Genetic Resources and Crop Evolution 65, 1937-1951.

Evanno, G., Regnaut, S., Goudet, J., 2005. Detecting the number of clusters of individuals using the software STRUCTURE: a simulation study. Molecular ecology 14, 2611-2620.

FAOSTAT, 2019. Food and Agriculture Organization of the United Nations. Available online: http://www.fao.org/faostat/en/ (accessed on 27 February 2020).

Ferreira, J.R., Pereira, J.F., Turchetto, C., Minella, E., Consoli, L., Delatorre, C.A., 2016. Assessment of genetic diversity in Brazilian barley using SSR markers. Genetics and molecular biology 39, 86-96.

Frankham, R., Ballou, J.D., Briscoe, D.A., 2010. Introduction to conservation genetics. 2 ed. Press Syndicate for the University of Cambridge, Cambridge.

Garstang, J.R., Spink, J.H., Suleimenov, M., Schillinger, W.F., McKenzie, R.H., Tanaka, D.L., Ceccarelli, S., Grando, S., Paynter, B.H., Fettell,
N.A., 2011. Cultural practices: Focus on major barley-producing regions, in: Ullrich, S.E. (Ed.), Barley: Production, improvement, and uses, Oxford, Wiley-Blackwell,, pp. 221-228.

Gougerdchi, V., Dezhsetan, S., Ebrahimi, M.A., Sadeghzadeh, B., Savari, S., 2014. Using SSR Markers For Assessment Genetic Diversity And Detection Drought Escape Candidate Genes In Barley Lines (Hordeum Vulgare L.). Plant Breeding and Seed Science 70, 3-14.

Govindaraj, M., Vetriventhan, M., Srinivasan, M., 2015. Importance of genetic diversity assessment in crop plants and its recent advances: an overview of its analytical perspectives. Genetics research international 2015, 1-14.

Greenbaum, G., Templeton, A.R., Zarmi, Y., Bar-David, S., 2014. Allelic richness following population founding events-a stochastic modeling framework incorporating gene flow and genetic drift. PloS one 9, 1-23.

Hamblin, M.T., Close, T.J., Bhat, P.R., Chao, S., Kling, J.G., Abraham, K.J., Blake, T., Brooks, W.S., Cooper, B., Griffey, C.A., 2010. Population structure and linkage disequilibrium in US barley germplasm: implications for association mapping. Crop Science 50, 556-566.

Hamza, S., Hamida, W.B., Rebaï, A., Harrabi, M., 2004. SSR-based genetic diversity assessment among Tunisian winter barley and relationship with morphological traits. Euphytica 135, 107-118.

Hayden, M., Nguyen, T., Waterman, A., McMichael, G., Chalmers, K., 2008. Application of multiplexready PCR for fluorescence-based SSR genotyping in barley and wheat. Molecular breeding 21, 271-281.

Hua, W., Zhang, X., Zhu, J., Shang, Y., Wang, J., Jia, Q., Li, C., Yang, J., 2015. A study of genetic diversity of colored barley (Hordeum vulgare L.) using SSR markers. Genetic Resources and Crop Evolution 62, 395-406.

Hübner, S., Höffken, M., Oren, E., Haseneyer, G., Stein, N., Graner, A., Schmid, K., Fridman, E., 2009. Strong correlation of wild barley (Hordeum spontaneum) population structure with temperature and precipitation variation. Molecular Ecology 18, 1523-1536.

Hussain, N.N., Adeel, H., 2017. Genetic Diversity of Iraqi Barley Species Differing in Their Tolerance to Drought by RAPD Analysis. Ibn AL-Haitham J. For Pure and Applied Science 28, 245-256.

Jaiswal, S., Pandey, S.P., Sharma, S., Prasad, R., Prasad, L., Verma, R., Joshi, A.K., 2010. Diversity in Indian barley (Hordeum vulgare) cultivars and identification of genotype-specific fingerprints 
using microsatellite markers. J. Genetics 89, 4654.

Jamali, S.H., Mohammadi, S.A., Sadeghzadeh, B., 2017. Association mapping for morphological traits relevant to registration of barley varieties. Spanish J. Agricultural Research 15, 1-13.

Jasim Aljumaili, S., Rafii, M., Latif, M., Sakimin, S.Z., Arolu, I.W., Miah, G., 2018. Genetic diversity of aromatic rice germplasm revealed by SSR markers. BioMed research international 2018, 111.

Kahodariya, J., Sabara, P., Vakharia, D., 2015. Assessment of genetic diversity in old world and new world cotton cultivars using RAPD and ISSR markers. International J. Biotechnology 14, 511-517.

Kilian, B., Özkan, H., Kohl, J., von Haeseler, A., Barale, F., Deusch, O., Brandolini, A., Yucel, C., Martin, W., Salamini, F., 2006. Haplotype structure at seven barley genes: relevance to gene pool bottlenecks, phylogeny of ear type and site of barley domestication. Molecular Genetics and Genomics 276, 230-241.

Kling, J.G., Hayes, P.M., Ullrich, S.E., 2004. Barley. Genetics and Breeding, in: Colin, W.W., Corke, H., Walker, C. (Eds.), Encyclopedia of grain science, Elsevier Ltd., Amsterdam, pp. 27-37.

Komatsuda, T., Pourkheirandish, M., He, C., Azhaguvel, P., Kanamori, H., Perovic, D., Stein, N., Graner, A., Wicker, T., Tagiri, A., 2007. Six-rowed barley originated from a mutation in a homeodomain-leucine zipper I-class homeobox gene. Proceedings of the National Academy of Sciences 104, 1424-1429.

Lakew, B., Henry, R.J., Ceccarelli, S., Grando, S., Eglinton, J., Baum, M., 2013. Genetic analysis and phenotypic associations for drought tolerance in Hordeum spontaneum introgression lines using SSR and SNP markers. Euphytica 189, 9-29.

Lenaerts, B., Collard, B.C., Demont, M., 2019. Improving global food security through accelerated plant breeding. Plant Science 287, 110207.

Lister, D.L., Jones, H., Oliveira, H.R., Petrie, C.A., Liu, X., Cockram, J., Kneale, C.J., Kovaleva, O., Jones, M.K., 2018. Barley heads east: Genetic analyses reveal routes of spread through diverse Eurasian landscapes. PloS one 13, 1-29.

Liu, S., Feuerstein, U., Luesink, W., Schulze, S., Asp, T., Studer, B., Becker, H.C., Dehmer, K.J., 2018. DArT, SNP, and SSR analyses of genetic diversity in Lolium perenne L. using bulk sampling. BMC genetics 19, 1-13.

Malysheva-Otto, L.V., Ganal, M.W., Röder, M.S., 2006. Analysis of molecular diversity, population structure and linkage disequilibrium in a worldwide survey of cultivated barley germplasm (Hordeum vulgare L.). BMC genetics 7, 1-14.

Massadeh, M.I., Abu-Romman, S.M., Odat, N.A., Hasan, M.K., Obeidat, M.S., Shatnawi, M.A., Qrunfleh, I.M., 2015. Identifying Selection Signatures Related to Domestication Process in Barley (Hordeum vulgare L.) Landraces of Jordan Using Microsatellite Markers. Jordan J. Biological Sciences 8, 307-313.

Mekonnon, B., Lakew, B., Dessalegn, T., 2015. Morphological diversity and association of traits in Ethiopian food barley (Hordeum vulgare L.) landraces in relation to regions of origin and altitudes. J Plant Breed Crop Sci 7, 243-253.

Mezghani-Khemakhem, M., Bouktila, D., Casse, N., Maaroufi, H., Makni, M., Makni, H., 2012. Development of new polymorphic microsatellite loci for the barley stem gall midge, Mayetiola hordei (Diptera: Cecidomyiidae) from an Enriched Library. International J. Molecular Sciences 13, 14446-14450.

Mohamed, E., Adel, E., 2012. Genetic diversity of some Saudi barley (Hordeum Vulgare L.) landraces based on microsatellite markers. African J. Biotechnology 11, 4826-4832.

Naceur, A.B., Chaabane, R., El-Faleh, M., Abdelly, C., Ramla, D., Nada, A., Sakr, M., 2012. Genetic diversity analysis of North Africa's barley using SSR markers. J. Genetic Engineering and Biotechnology 10, 13-21.

Nadeem, M.A., Nawaz, M.A., Shahid, M.Q., Doğan, Y., Comertpay, G., Yıldız, M., Hatipoğlu, R., Ahmad, F., Alsaleh, A., Labhane, N., 2018. DNA molecular markers in plant breeding: current status and recent advancements in genomic selection and genome editing. Biotechnology \& Biotechnological Equipment 32, 261-285.

Newman, R.K., Newman, C.W., 2008. Barley for food and health: Science, technology, and products. John Wiley \& Sons.

Oliver, R., Yang, C., Hu, G., Raboy, V., Zhang, M., 2009. Identification of PCR-based DNA markers flanking three low phytic acid mutant loci in barley. J. Plant Breeding and Crop Science 1, 087-093.

Pasam, R.K., Sharma, R., Walther, A., Özkan, H., Graner, A., Kilian, B., 2014. Genetic diversity and population structure in a legacy collection of spring barley landraces adapted to a wide range of climates. PLoS One 9, 1-29.

Poets, A.M., Fang, Z., Clegg, M.T., Morrell, P.L., 2015. Barley landraces are characterized by 
geographically heterogeneous genomic origins. Genome biology 16, 173.

Prada, D., 2009. Molecular population genetics and agronomic alleles in seed banks: searching for a needle in a haystack? J. Experimental Botany 60, 2541-2552.

Rahimi, M., Hervan, I.M., Valizadeh, M., Kajori, F., Ebrahimpour, F., 2014. Genetic Diversity among Wild and cultivated barley by ISSR Marker. Bulletin of Environment, Pharmacology and Life Sciences 3, 57-62.

Raoudha, A., Hatem, C.M.h., M'barek, B.N., Chaabane, R., Leîla, B.-K., Jeannette, B.H., 2007. Simple sequence repeat markers and physiological characterization of some local Tunisian barley accessions. J. Cell and Molecular Biology 6, 1929.

Russell, J., Fuller, J., Macaulay, M., Hatz, B., Jahoor, A., Powell, W., Waugh, R., 1997. Direct comparison of levels of genetic variation among barley accessions detected by RFLPs, AFLPs, SSRs and RAPDs. TAG Theoretical and Applied Genetics 95, 714-722.

Russell, J., Mascher, M., Dawson, I.K., Kyriakidis, S., Calixto, C., Freund, F., Bayer, M., Milne, I., Marshall-Griffiths, T., Heinen, S., 2016. Exome sequencing of geographically diverse barley landraces and wild relatives gives insights into environmental adaptation. Nature Genetics 48, 1024-1030.

Sallam, A., Alqudah, A.M., Dawood, M.F., Baenziger, P.S., Börner, A., 2019. Drought stress tolerance in wheat and barley: advances in physiology, breeding and genetics research. International $\mathrm{J}$. Molecular Sciences 20, 1-36.

Singh, P., A. K. Singh, M. Sharma, Salgotra, S., 2014. Genetic divergence study in improved bread wheat varieties (Triticum aestivum). African J. Agricultural Research 9, 507-512.

Sorkheh, K., Dehkordi, M.K., Ercisli, S., Hegedus, A., Halász, J., 2017. Comparison of traditional and new generation DNA markers declares high genetic diversity and differentiated population structure of wild almond species. Scientific reports $7,1-17$.

Stein, N., Herren, G., Keller, B., 2001. A new DNA extraction method for high-throughput marker analysis in a large-genome species such as Triticum aestivum. Plant breeding 120, 354-356.

Tahir, N.A.-R., 2014. Comparison of RAPD-PCR and SDS-PAGE techniques to evaluate genetic variation among nine barley varieties (Hordeum spp). Malaysian Applied Biology 43, 109-119.

Tanksley, S.D., McCouch, S.R., 1997. Seed banks and molecular maps: unlocking genetic potential from the wild. Science 277, 1063-1066.
Todorovska, E., Fasoula, D., Ioannides, I., 2019. Molecular Diversity in Bulgarian and Cypriot Barley Germplasm Collections-A Reference Point for Better Understanding, Exploitation and Improvement of Adaptiveness to Agro-Climatic Conditions. Biomedical J. Scientific \& Technical Research 12, 9459-9462.

Tricase, C., Amicarelli, V., Lamonaca, E., Rana, R.L., 2018. Economic analysis of the barley market and related uses, in: Tadele, Z. (Ed.), Grasses as Food and Feed, IntechOpen, p. 167.

Tyrka, M., Perovic, D., Wardyńska, A., Ordon, F., 2008. A new diagnostic SSR marker for selection of theRym4/Rym5 locus in barley breeding. J. Applied Genetics 49, 127-134.

Viruel, J., Haguenauer, A., Juin, M., Mirleau, F., Bouteiller, D., Boudagher-Kharrat, M., Ouahmane, L., La Malfa, S., Médail, F., Sanguin, H., 2018. Advances in genotyping microsatellite markers through sequencing and consequences of scoring methods for Ceratonia siliqua (Leguminosae). Applications in Plant Sciences 6, e01201.

Wang, J.-m., Yang, J.-m., Zhu, J.-h., Jia, Q.-j., Tao, Y.-z., 2010. Assessment of genetic diversity by simple sequence repeat markers among forty elite varieties in the germplasm for malting barley breeding. J. Zhejiang University-Science B 11, 792-800.

Weng, Y., Azhaguvel, P., Michels, G., Rudd, J., 2007. Cross-species transferability of microsatellite markers from six aphid (Hemiptera: Aphididae) species and their use for evaluating biotypic diversity in two cereal aphids. Insect molecular biology 16, 613-622.

Wicker, T., Schulman, A.H., Tanskanen, J., Spannagl, M., Twardziok, S., Mascher, M., Springer, N.M., Li, Q., Waugh, R., Li, C., 2017. The repetitive landscape of the $5100 \mathrm{Mbp}$ barley genome. Mobile DNA 8, 1-16.

Yadav, R.K., Gautam, S., Palikhey, E., Joshi, B.K., Ghimire, K.H., Gurung, R., Adhikari, A.R., Pudasaini, N., Dhakal, R., 2018. Agromorphological diversity of Nepalese naked barley landraces. Agriculture \& Food Security 7, $1-12$.

Yahiaoui, S., Igartua, E., Moralejo, M., Ramsay, L., Molina-Cano, J.L., Lasa, J., Gracia, M., Casas, A., 2008. Patterns of genetic and ecogeographical diversity in Spanish barleys. Theoretical and Applied Genetics 116, 271-282.

Zhang, M., Mao, W., Zhang, G., Wu, F., 2014. Development and characterization of polymorphic EST-SSR and genomic SSR markers for Tibetan annual wild barley. PLoS One 9, 1-10. 